\title{
Atendimento a pacientes dependentes de drogas: atuação conjunta do psicólogo e do psiquiatra ${ }^{1}$
}

\author{
Marli Ferreira Occhini \\ Marlene Galativicis Teixeira \\ Universidade São Judas Tadeu
}

\begin{abstract}
Resumo
Muito se tem discutido acerca da interrelação entre psicólogos e psiquiatras quanto ao tratamento multidisciplinar de seus pacientes, e este aspecto constituiu-se no objetivo principal desta investigação. $\mathrm{O}$ material utilizado constou de um roteiro de entrevista com perguntas abertas, analisado segundo o método de Lefèvre e Lefèvre, tendo como amostra três psicólogos e três psiquiatras em um ambulatório de uma instituição pública de saúde do Estado de São Paulo. As conclusões resultantes desta pesquisa revelam ainda existirem pontos de divergência entre as especialidades, mas sugerem perspectivas de entrosamento no que se refere ao entendimento e expectativas entre elas.
\end{abstract}

Palavras-chave: psicologia; psiquiatria; multidisciplinaridade

\begin{abstract}
Attendance of drug-dependent patients: psychologists and psychiatrists in team-work. The interrelationship amongst psychologists and psychiatrists has been an issue in terms of multidisciplinary team related to the treatment of their patients, and this aspect constituted the focus of this investigation. Three psychologists and three psychiatrists from a State Public Health Institution in Sao Paulo were interviewed and their responses to open questions were analyzed by means of the qualitative method proposed by Lefèvre and Lefèvre. The main conclusions reveal that there still are divergences amongst these specialties, but also that perspectives of mutual understanding of their professional roles can be seen.
\end{abstract}

Keywords: psychology; psychiatry; multidisciplinarity

$\mathrm{O}$ objetivo delineado para a pesquisa foi o de compreender a interrelação da equipe multidisciplinar (psiquiatria e psicologia) no tratamento da psicose induzida por drogas, buscando entender que fatores são contributivos para o bom desenvolvimento do trabalho em equipe e quais são desagregantes; as visões particulares de cada especialidade em relação à sua complementar; a participação da instituição nesse contexto e, também, desvendar a nebulosa questão da mescla de conhecimentos da outra especialidade que seriam necessários e contributivos para uma melhor interação sob o ponto de vista do estabelecimento de uma compreensão do universo a ser analisado frente a um paciente drogadito.

Buscamos, ainda, entender diferentes aspectos que podem ser determinantes nesta interação, tais como: como se delineia a trajetória profissional de ambas as especialidades e como ocorre a sua inserção no mercado hospitalar; qual a importância e a influência da instituição nesse contexto; que fatores são importantes na facilitação da formação do relacionamento e vínculo com o paciente; como interage a equipe no trato da resistência, adesão, abandono e reincidência ao tratamento por parte do paciente; qual a importância dos responsáveis pelo drogadito e como a equipe multidisciplinar trata essa questão. No âmbito das especialidades, procuramos compreender qual a visão particularizada de cada uma em relação à sua complementar no que diz respeito a facilidades e dificuldades em seu relacionamento dentro da instituição como um todo e, em particular, no âmbito ambulatorial. Qual a percepção advinda da atuação conjunta destas especialidades na equipe multidisciplinar em ambos os contextos (institucional e ambulatorial) e, finalmente, quais seriam os conhecimentos necessários, para o bom desenvolvimento do trabalho em equipe, por parte destas especialidades em relação à sua complementar.

Uma vez que essa área se constituía em um todo desconhecido para as pesquisadoras, sentimo-nos compelidas a efetuar um levantamento que fosse o mais abrangente possível a fim de que pudéssemos acompanhar quaisquer afirmações que, eventualmente, surgissem por parte dos entrevistados. Dessa forma, iniciamos nossas pesquisas no sentido 
de conhecer um pouco melhor sobre as drogas em termos de conceituação, efeitos decorrentes do uso, dados epidemiológicos e comorbidades, além da visão destas sob o prisma neurofisiológico e, mais especificamente, as patologias por elas induzidas, abrangendo os diagnósticos e tratamentos utilizados.

A bibliografia pesquisada nos ofereceu informações acerca das drogas em termos de conceituação, seus efeitos nos organismos, transtornos decorrentes, comorbidades, sua ação sob o prisma neurofisiológico, além de informações acerca do quadro nosológico e critérios diagnósticos referentes aos transtornos relatados e sua diferenciação em relação à droga consumida (American Psychiatric Association, 2000, World Health Organization, 1993); bem como material que referenciasse os tipos de tratamentos utilizados tanto do ponto de vista medicamentoso quanto do ponto de vista psicoterápico.

Porém, nada foi encontrado, na literatura nacional disponível, que versasse sobre a interrelação entre psicólogos e psiquiatras no contexto multidisciplinar de uma instituição: como a mesma se processa, quais seriam as possíveis dificuldades ou fatores facilitadores para uma boa interação das especialidades e para o desenvolvimento do trabalho em equipe. Tampouco se encontrou qualquer informação quanto à realidade das instituições no que concerne à psicologia como campo de saber necessário ao desenvolvimento do tratamento tanto no trato do usuário de drogas quanto nos transtornos decorrentes do uso de drogas.

Diante desta ausência, por si só bastante significativa, tentamos encontrar alguns parâmetros que nos permitissem vislumbrar qual o papel do psicólogo dentro de uma equipe multidisciplinar, como este profissional é percebido e quais as dificuldades mais freqüentemente encontradas no desempenho de suas funções dentro de uma instituição.

\section{Método}

\section{Participantes}

Participaram profissionais da área "psi” que trabalham em ambulatório específico para tratamento da drogadição em uma instituição hospitalar da rede pública de saúde, situada em São Paulo. Compôs-se a referida amostra de três psiquiatras formados entre o ano de 1994 e 2000, que trabalham na instituição entre 1 a 10 anos e se reportam, funcionalmente, ao coordenador do ambulatório, tendo dois deles o título de mestre. Participaram também três psicólogas formadas entre o ano de 1991 e 1995, com diversos cursos de especialização, tanto na área de psicologia, quanto no âmbito específico de drogas, e que contam de 7 a 8 anos de dedicação à instituição. Todas se reportam aos psiquiatras e ao coordenador atuantes no ambulatório. Embora existam diferenças quanto ao tempo de formação e, também, quanto ao tempo de trabalho na instituição, estes fatores não influenciam os resultados obtidos em função de existirem normas estabelecidas tanto para o tratamento quanto para o estabelecimento da relação interativa entre as especialidades.

\section{Material}

O trabalho desenvolvido caracterizou-se como uma pesquisa de campo, baseando-se na coleta de respostas obtidas através de um roteiro de entrevista, com perguntas abertas, analisadas segundo o método de análise qualitativa descrito por Lefèvre e Lefèvre (2003), que tem embasamento no pensamento coletivo como objeto de investigação.

A tabulação dos dados de pesquisa foi feita através da leitura dessas respostas e da identificação de elementos (palavra, conceito, expressão) que nos apresentaram a essência do sentido da resposta. Tais elementos constituíram as categorias que nos forneceram a equivalência dos depoimentos (expressão de uma mesma idéia). Dessa forma, as categorias forneceram a condição de cientificidade, uma vez que os discursos puderam ser equalizados nas classes constituídas.

\section{Instrumento}

O instrumento utilizado compreendeu um roteiro de entrevista composto por 11 itens classificatórios do profissional e 26 perguntas abertas referentes ao tratamento e interação multidisciplinar no tratamento das psicoses induzidas por drogas.

\section{Procedimento}

Como primeira etapa desta pesquisa, o projeto foi submetido à apreciação do Comitê de Ética da Universidade São Judas Tadeu, cujo parecer favorável permitiu-nos iniciar o trabalho de campo. O projeto foi, também, submetido e aprovado pela coordenação do ambulatório convidado. Os entrevistados foram contatados por telefone, a fim de que pudéssemos obter sua anuência em participar e, assim, agendarmos as entrevistas, que ocorreram individualmente e no local de trabalho dos entrevistados. Cada um dos entrevistados leu e assinou o Termo de Consentimento Livre e Esclarecido, após o que foram aplicados os referidos roteiros. As entrevistas foram gravadas, transcritas e analisadas em relação ao seu conteúdo, obedecendo ao percurso programado no roteiro de entrevista previamente elaborado, gerando conceitos, oriundos das duas especialidades de saúde.

\section{Resultados e Discussão}

Objetivando melhor abrangência quanto à análise dos resultados, processamos o agrupamento das 26 respostas às entrevistas de forma que todos os aspectos levantados fossem avaliados. Os 10 tópicos assim formados são apresentados a seguir.

\section{Trajetória profissional e inserção no mercado hospitalar}

A trajetória profissional, bem como a inserção no mercado hospitalar, apresenta percursos bem distintos entre as duas especialidades. Segundo os psiquiatras entrevistados, sua trajetória profissional implica o envolvimento com o ambiente hospitalar ainda no período da residência médica, ficando, desta forma, estabelecida uma maior facilidade de inserção no mercado. Constatamos que isto ocorre mesmo que esses 
profissionais apresentem deficiências em sua formação no que diz respeito à área da psicologia.

De acordo com os psicólogos entrevistados, no entanto, o caminho a ser percorrido depois de formados é árduo e por muitas vezes dificultado por aspectos financeiros e necessidades de cursos de especialização. Normalmente, após sua formatura, os psicólogos se vêem ainda sem condições de desempenho do trabalho clínico, com poucos pacientes (quando os têm) e sentem-se levados ao desempenho de trabalhos voluntários em ambulatórios, criados para o desenvolvimento de projetos de mestrado e doutorado da área de psiquiatria, ao mesmo tempo em que sentem a necessidade de complementação de seu conhecimento em áreas não cobertas pelo seu curso de graduação. Especificamente na área de drogas, os psicólogos iniciaram-se na Instituição por meio de indicações para voluntariado em equipe de psiquiatras lotada em um ambulatório específico. Sua formação baseou-se, inicialmente, na prática clínica e, por gostarem do trabalho que estava sendo desenvolvido, foram em busca de maiores conhecimentos na área da psiquiatria. Após alguns anos de trabalho voluntário, conseguiram remuneração e adequação ao ambiente de trabalho. Dessa forma, sua inserção no meio hospitalar advém desses primeiros contatos com especializações em ambulatórios de grandes instituições.

Concluímos, nesta avaliação, que a disparidade quanto à iniciação dessas especialidades na área hospitalar reflete maiores dificuldades para o profissional da área de psicologia, o qual, além de ter de superar a questão da dificuldade oferecida para seu ingresso na área Psi (a não ser quando este se dá através do trabalho voluntário), precisará se dispor - diferentemente da outra especialidade - a buscar estudos complementares acerca da outra área do saber, a fim de ampliar seu horizonte de conhecimentos e poder estar mais próximo das necessidades que envolvem a especificidade do trabalho com drogaditos.

\section{A Instituição}

A Instituição, em si, é vista como sendo uma entidade organizada que oferece facilidades aos que a ela pertencem e são consideradas de grande importância, uma vez que oferecem segurança e uma retaguarda que apóia os profissionais, além de lhes dar suporte e continência. Significa também um estímulo à produção, à transmissão e aquisição de conhecimentos, embora não seja estimulada para o desenvolvimento na área da psicologia, segundo os psicólogos entrevistados.Os psiquiatras salientam a necessidade de a Instituição rever seus conceitos com relação ao paciente psiquiátrico e, mais especificamente nesse ambulatório, ao dependente químico, restituindo-lhes o status de pessoa do qual estão hoje destituídos.

Ao mesmo tempo, ambas as especialidades assinalam existir, por parte da Instituição, uma supervalorização do biológico em detrimento do psicológico.

\section{Relacionamento e vínculo}

É fato inconteste para nós, e também defendido pelas especialidades pesquisadas, que o progresso de qualquer tratamento médico/psicoterápico depende muito de um bom estabelecimento do vínculo entre o paciente e seu médico. Para que o tratamento alcance sua eficácia, deve haver uma cumplicidade e parceria entre ambos, de forma que conversem livremente e sem barreiras.

Com relação a esse parecer, Bucher (1992) ressalta que dentro da equipe multidisciplinar, que abarca o tratamento do drogadito, seja possibilitado ao paciente o estabelecimento de uma relação afetiva (vínculo) com o terapeuta com o qual se sintonize melhor, a fim de que esse profissional possa superar barreiras oriundas de desconfiança e, assim, o paciente possa estabelecer um desenvolvimento transferencial com o profissional.

Constata-se que trabalhar com pacientes drogaditos é uma tarefa delicada, que requer muito cuidado por parte dos profissionais envolvidos. O usuário, que é visto pela sociedade de maneira estereotipada (bandido, criminoso, vagabundo, etc.) e que é, muitas vezes, rejeitado no próprio ambiente familiar, necessita encontrar no profissional de saúde mental alguém que o veja como uma pessoa necessitada de ajuda, que o apóie em seu sofrimento e que reconheça suas dificuldades.

Os especialistas entrevistados neste trabalho apontaram algumas situações que podem provocar dificuldades no estabelecimento de relacionamento e vínculo com os drogaditos durante o tratamento, e para os quais precisamos ficar atentos: a importância da troca de informações entre a equipe (a fim de que se evite a manipulação do paciente quando de seu desejo de negar a doença); a necessidade de uma equipe integrada e afastamento de sensibilidades pessoais entre os profissionais envolvidos; disponibilidade de escuta e qualidade do atendimento; a existência atual de uma equipe insuficiente para abarcar os diferentes contextos; e, por fim, um baixo grau de envolvimento do próprio paciente com o reconhecimento de seu problema e com a relação de cura esperada, além de sua busca por uma solução menos trabalhosa, e menos sofrida, através de um medicamento milagroso.

Em contrapartida, facilidades são, também, por eles apontadas: o despojamento dos aspectos pessoais dentro da equipe (que permite a aceitação da vinculação do paciente com um ou outro elemento da equipe), um posicionamento livre de estereótipos, uma maior habilidade em lidar com as diferenças e conseguir a percepção do paciente quanto à reestruturação do seu estilo de vida e da própria vida, são fatores que o auxiliam na manutenção e no fortalecimento do vínculo terapêutico.

\section{Resistência ao tratamento}

Sabe-se que a resistência ao tratamento é uma presença constante em qualquer procedimento que envolva alterações substanciais na vida das pessoas e pode se dar antes mesmo que o tratamento seja estabelecido, conforme citam Fontanella e Turato (2002) em seu estudo, afirmando que a maioria dos drogaditos adia a procura por tratamento simplesmente por não pensarem nessa possibilidade (por negarem a própria condição), ou por não acreditarem na gravidade do problema, 
ou, ainda, por não acreditarem que o tratamento possa resolver sua condição.

Uma vez estabelecida a procura por assistência, constata-se que a resistência ao tratamento assume várias formas e constitui um elemento importante a ser considerado no âmbito do tratamento multidisciplinar, isso porque, dada a sua variedade, envolve diferentes tipos de abordagens, seja no aspecto biológico (medicamentoso), seja no aspecto psíquico (terapias e análise situacionais) ou social (familiares e rede de suporte). Dessa forma, foram citados pelos especialistas alguns tipos de resistência ao tratamento, que tanto podem surgir no contato com os psiquiatras, em suas consultas de rotina, quanto com os psicólogos, em seus atendimentos semanais, quais sejam: (1) pacientes que são resistentes à psicoterapia e não querem expor seus problemas pelo desgaste da elaboração e, também, como uma forma de negá-los; dessa forma, querem apenas que lhes seja administrado um medicamento; (2) o alto índice de recaídas e o abandono por parte dos pacientes (também caracterizados como resistência), podem ser reflexos da baixa efetividade apresentada pelos tratamentos, em função dos parâmetros que regulam a dependência química; (3) a dificuldade do paciente em lidar com sua própria problemática: dificuldade em aceitar a dependência como problema; em seguir as regras que lhe são impostas pelo tratamento; sua própria indisciplina no seguimento e até mesmo sua impaciência pela busca de resultados; (4) a própria linguagem do profissional pode ser um empecilho para que o sujeito possa aceitar o trabalho interventivo, por não entender o que lhe é dito ou solicitado e, muitas vezes, para não ser identificado como um paciente psiquiátrico; (5) quando o tratamento passa a ser um problema para aqueles que solicitaram esse tipo de intervenção (chefias que criam impedimentos para a continuidade do tratamento), temos estabelecida uma resistência de característica diversa, pois se reflete não mais pelo paciente e sim pelo grupo de suporte atuando sobre o paciente e (6) as condições físicas ambientais em que o tratamento é aplicado podem, também, servir como justificativas para a resistência.

Para a superação das resistências, ambas as especialidades assinalam algumas questões que, por serem de alta relevância, nunca caminham de forma isolada, mas sim compõem um conjunto de ações, conceitos e estratégias que perfazem a totalidade que abrange o tratamento dos drogaditos: (1) disponibilidade do profissional para tomar a resistência como uma oportunidade de abertura à percepção do problema (momento em que o paciente pode estar mais sensível à compreensão de seus próprios problemas), promovendo o fortalecimento do vínculo; (2) da mesma forma, é essencial que não se “feche” a questão no caso da resistência e não se estabeleçam definições que dificultariam outras possibilidades de lidar com o problema, o que permitiria novas alternativas de fuga; (3) os níveis de conquista a serem alcançados pelo tratamento devem ser definidos a partir do que a pessoa tem como seu desejo (o que quer como saúde e relação com a droga) e (4) a necessidade da participação da família e, mesmo, de toda a rede de suporte, para evitar que os diferentes tipos de resistência apresentados pelos pacientes, que são onipotentes e não confiáveis em seus relatos, superem a ação conjunta do grupo envolvido neste trabalho.

No que concerne às frustrações geradas nos profissionais, observamos que, em função de todas as possibilidades de resistência que se sucedem, estes procuram evitar cair no desalento e no descrédito quanto ao trabalho desenvolvido, a fim de que toda a equipe possa se auto-sustentar e dar continuidade a um trabalho que, por si só, apresenta resultados apenas em longo prazo e que, portanto, demanda persistência e perseverança.

No entanto, ao analisarmos o que é exposto pelos especialistas, detectamos facilidades proporcionadas pela equipe multidisciplinar no trato da questão da resistência do paciente ao tratamento: a multidisciplinaridade permite que o sujeito se vincule com o profissional com o qual se sente mais à vontade, (por maior afinidade ou por um linguajar a ele mais compreensível), o que ocorre com mais freqüência com o psicólogo (através da psicoterapia e seus encontros semanais) do que com o psiquiatra, que dispõe de menos tempo em sua consulta com o paciente e o vê apenas uma vez por mês e o próprio contexto hospitalar constitui uma facilidade. $\mathrm{O}$ paciente percebe a importância desse espaço: a importância do atendimento médico e do atendimento psicológico.

\section{Abandono e adesão ao tratamento}

Quanto à questão do abandono ao tratamento, o que se observa é uma relação de diferentes fatores que para isso concorrem, sendo que um dos primordiais se refere ao fato de ser a droga um elemento que tem um significado na vida do paciente, substituindo uma falta em seu viver, o que implica saber através do processo psicoterapêutico a que ela serve, a que falta ela se propõe substituir. Dentro desse contexto, o abandono ao tratamento é justificado pela evitação do enfrentamento do problema subjacente, que é maior do que o uso da própria droga, uma vez que aquele tratamento implica dor e sofrimento pela elaboração do problema primeiro, pela elaboração de seu sofrer.

Castel (1997) destaca também que o abandono ao tratamento pode ser uma condição estabelecida pelo paciente:

Talvez os pacientes determinem o tempo de tratamento que julgam necessário, independente do julgamento dos profissionais envolvidos. Ou, ainda, o fato de melhorar implique em assumir novas responsabilidades e mudar prioridades (trabalhar, por exemplo). O tempo dedicado ao tratamento passaria então a ser dirigido a outras atividades. (p. 123)

Os psiquiatras assinalam que, muitas vezes, os efeitos colaterais ocasionados pelas diferentes medicações administradas podem incorrer em abandono (pelo desconforto ocasionado ou pela própria restrição pessoal que implicam). Observamos, por outro lado, que as regras de participação no processo terapêutico, estabelecidas pelos profissionais da equipe multidisciplinar, e que objetivam um comprometimento por parte do paciente, podem também ser bastante aversivas pela sua essência disciplinadora, e esbarram com a dificuldade em se- 
guir regras e em obedecer a um esquema disciplinar. Com isso, a fuga parece ser uma boa alternativa ao tratamento.

Os psicólogos ressaltam que um aspecto importante a ser considerado, como facilitador à adesão do paciente ao tratamento, consiste na assistência psicoterápica prestada através da terapia de grupo no trato de suas questões pessoais e de sua relação com a droga (como fator de integração do paciente) e para que ele se descubra não isolado em sua busca pela recuperação.

Andrade, Castel e Hochgraf (1995) ressaltam que, independente dos tratamentos a serem aplicados ao usuário, devese ter em conta que é fundamental existir o desejo de se tratar por parte do paciente e que tal fator se constitui em um poderoso elemento para a adesão ao tratamento.

Pudemos, assim, constatar que a equipe multidisciplinar, através de sua permeabilidade e integração, é de extrema importância no trato dessas questões, proporcionando facilidades para que haja adesão ao tratamento, seja através de discussão e análise constante do trabalho em equipe (que permitem uma avaliação das dificuldades intercorrentes entre o profissional e o paciente ou com algum profissional em relação a outro), seja através da busca do que está interferindo na dinâmica do tratamento (e no trabalho de elucidação desses problemas).

\section{Reincidência na drogadição}

O tratamento da drogadição envolve a questão da reincidência (recaída) e este é um aspecto de relevada importância, pois, dependendo de como essa condição é percebida, recebida e tratada pelos profissionais, a resposta do paciente pode ser de abandono do tratamento ou de um restabelecimento do vínculo com a equipe e um retorno mais consciente ao processo. A forma de tratar o sofrimento do paciente (fracasso pessoal sentido pela reincidência) reside na capacidade dos profissionais em demonstrar ao paciente que essa ocorrência não significa um fracasso, e sim, que a recaída é esperada, encorajando-o a continuar com o tratamento.

Conforme referenciado por Lucena (1987), a farmacodependência corresponde a um estado psíquico e, às vezes, físico, ligados à interação entre o organismo e a droga. Essa afirmação sugere que a reincidência é uma conseqüência do próprio tratamento, uma vez que ele distancia o paciente daquela que lhe traz a vivência do prazer e lhe ocasiona o mal-estar da privação.

Bucher (1992), confirmando as premissas acima, destaca que:

as dimensões farmacológicas, psicológicas e sociais do uso e abuso de drogas estão indissociavelmente mescladas e perfazem juntas o problema da drogadição, resultando de um encontro estruturalmente semelhante nos mais diversos contextos onde ocorrer, mas marcado pela singularidade de um determinado usuário e do seu contato subjetivo com a droga, dentro de seu percurso de vida estritamente pessoal. (pp. 230-231)

E, logo a seguir, acrescenta que:
Qualquer que seja a área da estruturação humana, a falta pode ali se inscrever e suscitar a sensação de um vazio, de um dano irreparável, de uma privação incomensurável e sem possibilidade de preenchimento, mas suscitando uma ânsia insaciável e obsedante de consegui-lo um dia... A entrega às drogas deixa-se entender então como uma resposta específica, sintoma - e não causa - da presença intolerável de uma ausência vivida como mentalmente mutiladora e enganadora. (p. 237)

Com relação a esse aspecto, Lucena (1987) também faz uma ressalva importante ao destacar que a dependência psicológica, assinalada pela presença de sintomas decorrentes da abstinência do uso de drogas (ansiedade, sensação de vazio, dificuldade de concentração, entre outros), dificulta o tratamento e faz antever que ele não pode ser resolvido de forma rápida e simples como a dependência física.

Outra dificuldade, observada pelos psicólogos e psiquiatras com relação à reincidência na drogadição, é o fato desta pertencer, enquanto parte da vida do sujeito, aos âmbitos familiar, social e laboral do usuário, ficando difícil não ocorrer recaída do drogadito. Além disso, é especificado que a droga expressa o significado que tem para o paciente, seja na forma de seu desejo interior, seja como um elemento de alívio para suas dificuldades.

Vários pontos facilitadores, relacionados à inibição da reincidência na drogadição, foram apontados pelos profissionais entrevistados no sentido de se alcançar o objetivo maior que é a abstinência.

Foram apontados pelos psiquiatras: (1) ressaltar os erros cometidos para que não ocorram novamente e mostrar que o abandono ao tratamento agravou a sua situação; (2) buscar maiores pontos de adesão, como a vinculação a um grupo, objetivando a chegada à abstinência através de algum caminho e (3) trabalhar com dinâmica de grupo e terapia familiar, pois estas facilitam uma visão mais ampla do que está acontecendo com o paciente.

Pelos psicólogos foi apontado: (1) discutir o caso numa equipe multidisciplinar, pois isto acarreta uma visão mais abrangente do caso apresentado pelo paciente; (2) não punição a um reincidente e valorização de seus pequenos sucessos e (3) estimular o paciente, de forma franca, a relatar a reincidência a seu médico e trazer novamente o reincidente ao grupo, seja pela convocação automática dos faltantes para a semana seguinte, seja pelo próprio grupo, uma vez que em muitos casos são conhecidos e têm certa facilidade em se encontrar.

\section{Responsáveis pelos drogaditos}

Além da família, outros elementos fazem parte da questão da responsabilidade em relação aos drogaditos, considerando-se que o meio social e laboral são de influência no desenvolvimento do processo terapêutico e na manutenção do esforço conjunto de resgate desse sujeito à qualidade de ser completo e com condições de enfrentar suas questões de modo mais saudável.

A primeira observação relevante prende-se ao fato de que conseguir o envolvimento dos familiares no tratamento 
do dependente químico é uma tarefa árdua. O afastamento dos familiares pode ser até compreensível (muito embora isso não os isente de forma alguma de sua parcela de responsabilidade na problemática do paciente), se pensarmos no desgaste da relação do grupo familiar. Quando pensamos em desgaste, imaginamos problemas da ordem de agressões físicas e verbais; desvio de dinheiro e objetos para aquisição de drogas; problemas com a polícia; dificuldades de relacionamento social; instabilidade no emprego; situações que são passíveis de ser localizadas no âmbito familiar e social do drogadito.

Ferreira, Leite, Hochgraf e Zilberman (2001) ressaltam aspectos importantes no que concerne à unidade familiar do dependente de drogas e na forma como devem ser tratados esses aspectos a fim de que se possa ter como expectativa um melhor envolvimento tanto da família quanto do próprio drogadito:

As dependências e suas complicações promovem alterações no funcionamento da dinâmica familiar e, muitas vezes, por estar a família acomodada ao uso de drogas de um de seus membros, tende a reforçá-lo. É a chamada co-dependência. Desta forma, a terapia familiar concomitante ao tratamento do paciente é fundamental para o reconhecimento dos aspectos interpessoais da dependência, avaliação clara da patologia familiar subjacente à dependência, além da transmissão de conhecimentos acerca das drogas, seus efeitos, risco de recaídas e como lidar com elas, bem como demonstrar a necessidade do apoio familiar ao dependente ao programa de tratamento. (p. 346)

Quando se analisa a dinâmica familiar, essa acaba por revelar qual a implicação do grupo no contexto da droga, bem como suas dificuldades de interação com o paciente. A família acaba se desestruturando e se distanciando do dependente justamente em função da própria desestruturação. Segundo os psicólogos entrevistados, essa questão precisa ser trabalhada numa terapia familiar fundamentada numa visão sistêmica, em que se busca a modificação dos paradigmas estabelecidos por aquela dinâmica. Assim, quando se promovem alterações em um dos integrantes, espera-se que todo o restante do sistema se modifique.

Mas não são apenas dificuldades que são identificadas no tratamento com os responsáveis pelos drogaditos. São também citadas algumas facilidades. Os profissionais entrevistados (psicólogos e psiquiatras) assinalam que uma abordagem junto aos familiares em relação aos problemas ocorridos nos tratamentos anteriores, que culminaram no seu abandono, é uma das facilidades identificadas, pois proporciona aos responsáveis um pouco mais de segurança, uma vez que demonstra a preocupação da equipe quanto ao tratamento dispensado ao dependente químico.

Ao final, pode-se constatar que é o psicólogo quem consegue uma maior aproximação com o drogadito e seus familiares. Isso pode ser observado através do papel do terapeuta familiar, que tem uma função essencial: inserir o sujeito no tratamento, mostrar que o problema não é só dele e que existe alguém com quem dividir suas aflições. O paciente que se envolve, que entende as orientações passadas e colabora consigo próprio, acaba por atrair, no grupo, outros pacientes para o tratamento.

\section{Especialidade complementar}

Neste quesito foram apontadas dificuldades relevantes que mereceriam um tratamento por parte da Instituição no sentido de valorização de si mesma, enquanto complexo de referência no contexto do tratamento do ser humano, e dos próprios elementos de seu quadro de colaboradores, enquanto seres humanos envolvidos no contexto hospitalar.

Os psiquiatras, de modo geral, assinalam as seguintes dificuldades: (1) a subvalorização do psicólogo, por conta de uma carência de pesquisas na área, justificando essa posição pela visão de que sua ausência se deve à dificuldade de se objetivar o que é subjetivo; (2) a formação das duas especialidades que direciona o trabalho de ambas para um contexto individual e a debilidade de seus currículos no que concerne à formação da outra especialidade (ambas desconhecem os pontos principais de conjugação de seu trabalho) ocasionam dificuldades de ajustes e entendimentos no trabalho em equipe e (3) a existência de uma maior onipotência por parte do corpo médico em relação ao poder isolado de tratamento, uma vez que sua formação o compele a uma visão unilateral e concentrada no biológico em detrimento do psicológico, disso resultando sua maior dificuldade de trabalho em equipe. Esta condição é menos presente na psicologia, uma vez que busca a contextualização do tratamento sob os diferentes ângulos a ele pertinentes (contexto biopsicossocial).

Quanto aos psicólogos, esses reconhecem esse status e referem que: (1) apesar de haver escuta aos assinalamentos feitos pela psicologia, existe um distanciamento discriminatório por parte da área médica em relação à esfera da psicologia; (2) há uma urgência, por parte da equipe médica, para o estabelecimento de diagnósticos, dificultando o trabalho em equipe, uma vez que os diagnósticos psicológicos não podem ser tão imediatistas quanto se espera, pois nem sempre o DSM-IV ou o CID-10 serão tão abrangentes para que se possa conceber o paciente em sua totalidade apenas com os preenchimentos de determinadas características; (3) há necessidade de atendimentos psicoterápicos em nível individual, como ação complementar à terapia de grupo, uma vez que não se podem abarcar as questões de cada um nesse tipo de atendimento; porém, isto se mostra inviável dentro do contexto de urgência e de custos no âmbito da Instituição; (4) a diferença de tempo em termos de tratamento entre o medicamentoso e o psicológico gera um descompasso entre os atendimentos, provocando uma saturação na lista de espera dos atendimentos psicológicos, que não conseguem abarcar o volume de pacientes recebidos dos psiquiatras; (5) em nível institucional, existe a dificuldade de se deixar a posição individual e estabelecer uma mentalidade de grupo, em função da existência de vaidades pessoais, competitividade, insegurança quanto à posição do outro no contexto multidisciplinar, e a existência de posições individu- 
alistas, que dificultam o exercício do trabalho conjunto; (6) o não reconhecimento do psicólogo pela Instituição como profissional qualificado e como parte de outro corpo do saber necessário ao tratamento gera a subordinação de uma especialidade à outra e a eventual desqualificação do trabalho executado, além dos ressentimentos pessoais advindos desse processo, e (7) há dificuldades éticas (no contexto da Instituição) no que concerne à reserva de mercado que se estabelece por parte das especialidades, gerando disputas em termos de número de pacientes em tratamento, seja com o retardo de encaminhamento de uma especialidade para a outra, seja pelo fato de que os médicos consideram que a psicoterapia é um procedimento médico, o que gera discussões infrutíferas entre as especialidades.

Os psiquiatras destacam a importância da psicologia para a avaliação da estrutura de personalidade do sujeito e do comportamento manifesto nos pacientes, salientando que por ter o psicólogo uma visão diferente daquela do médico, ele pode perceber aspectos que passam despercebidos para este. Assinalam, também, que o fato de se poder estabelecer uma relativa divisão de responsabilidades do fracasso entre paciente e equipe encoraja o grupo a pensar conjuntamente possíveis soluções para as diferentes questões e justificativas relativas à situação que se apresenta no contexto do tratamento, o que também é percebido pelos psicólogos. Já estes registram que o contar com o auxílio do médico em questões específicas da medicação e da própria medicina, bem como a discussão dos encaminhamentos e internação de pacientes, são aspectos relevantes para o bom desempenho de suas funções.

As propostas apontadas, pelos especialistas, para solucionar as divergências entre as especialidades abrangem diferentes e importantes aspectos, como: (1) uma boa formação acadêmica e ética possibilita a existência de uma visão mais clara acerca das questões do paciente e, também, acerca do que seria a real atribuição de cada uma das especialidades; (2) maior domínio das técnicas, de parte a parte, permitiria uma melhor interação entre as especialidades e melhor discussão das propostas de tratamento, considerando-se o resultado conjunto das intervenções propostas por ambas; (3) atribuição de normas específicas para o tratamento (relativas ao tempo), visando à necessidade de cada especialidade; (4) delimitação de atribuições às especialidades (objetivando evitar situações polêmicas), bem como normas para a preparação de alta do paciente; e, ainda, o estabelecimento de normas em termos de tratamento farmacológico (para a fissura e a co-morbidade), e para o tratamento psicológico (no que se refere às questões do indivíduo), além de se considerar também a rede de suporte para que todo o conjunto de atuações possa dar conta das questões inerentes ao funcionamento do paciente; (5) reconhecimento das limitações inerentes a cada especialidade e que restringem o atendimento do paciente como um todo por um só especialista; (6) necessidade de maior participação da área de psicologia no desenvolvimento da pesquisas que consubstanciem a área e fortaleçam o respeito ao desempenho de suas funções; e
(7) necessidade de reuniões para a discussão de casos com toda a equipe reunida (o que ainda hoje não ocorre), e melhor remuneração para o psicólogo, uma vez que essa especialidade, por ser pouco valorizada, tem rendimentos bem inferiores aos do corpo médico.

O que pudemos observar é que ambas as especialidades têm muito a oferecer uma à outra em termos de preenchimento de lacunas em suas formações, embora esse ainda não seja, de modo geral, um processo de troca bem fundamentado em todas as situações de trabalho em equipe. Falta, também, um maior reconhecimento dos valores individuais de cada especialidade, uma vez que situações de conflito se estabelecem em decorrência das vivências e posicionamentos individuais, que predominam sobre uma determinação conjunta e coerente de suas atribuições e respeito profissional.

\section{Equipe multidisciplinar na instituição}

As questões de maior importância, no âmbito do trabalho multidisciplinar, concentram-se na visão que têm entre si as duas especialidades, que podem gerar dificuldades para o relacionamento entre elas e para o desenvolvimento de um bom trabalho em equipe. No que concerne à atuação conjunta das duas especialidades nesse ambulatório, os psiquiatras entrevistados ressaltam a importância dos psicólogos, pois consideram que, embora as duas especialidades tenham um olhar diferente sobre o paciente, se complementam na avaliação da estruturação e formação do indivíduo, uma vez que se busca uma visão do paciente em sua totalidade e não como pessoa entendida apenas sob o prisma organicista. Os psicólogos, por sua vez, entendem que o contexto que envolve o paciente é da ordem do biopsicossocial, não sendo possível dessa forma a concentração do tratamento no nível biológico.

\section{Conhecimentos da área complementar}

Tanto os psiquiatras quanto os psicólogos reconhecem a existência de lacunas em sua formação. Constatamos que o ideal seria que em suas grades curriculares existissem esses elementos. Porém, dada a sua inexistência (o que se constata ao analisar os currículos de ambas as especialidades), faz-se necessária uma complementação, mesmo que por vias não do domínio do curso regular, pois o melhor conhecimento recíproco permitiria um funcionamento adequado da equipe, além de um debate produtivo entre as duas especialidades, sem que ocorressem ingerências ou aconselhamentos desnecessários de parte a parte, permitindo o estabelecimento de um bom entendimento entre os profissionais da área, no que concerne à discussão e ao planejamento de metas para o tratamento.

São, assim, referidos pelos psiquiatras como conhecimentos necessários aos psicólogos: (1) conhecimento e gosto pelo biológico, pois, mesmo não prescrevendo, há de se reconhecer que o entendimento sobre os mecanismos farmacológicos é necessário para uma melhor avaliação de suas ações e efeitos no organismo, assim como para evitar embates desnecessários com a área da psiquiatria, além de oferecer melhor suporte e orientação ao paciente e ajudar a 
combater certo dogmatismo ainda presente na área da psicologia em relação a esse quesito; (2) conhecimentos epidemiológicos acerca da droga, da base química da dependência, do mecanismo químico do uso da droga, da importância dos neurotransmissores e sinapses, da dinâmica do efeito da intoxicação, ou seja, a droga sob o ponto de vista neuropsicológico e bioquímico; (3) conhecimento, no contexto médico, de diagnóstico e tratamento, ou seja, dos quadros psiquiátricos presentes e das alterações qualitativas do funcionamento mental decorrentes do uso de drogas, bem como quais seriam os tratamentos farmacológicos adequados nesses casos, permitindo a troca saudável de informações acerca do bem-estar do paciente e impedindo a manipulação dos pacientes quando da falta de ajustamento à medicação; e (4) conhecimento da questão cultural vinculada ao debate das drogas, evitando que o usuário de drogas seja estereotipado também no âmbito do tratamento ambulatorial.

Em contrapartida, os psicólogos assinalam serem conhecimentos necessários aos psiquiatras: (1) conhecimento dos teóricos da psicologia e suas linhas de pensamento e dos fundamentos e instrumentos da psicologia (uma vez que o diagnóstico se faz pela transferência e contra-transferência e o psiquiatra não está ausente desse movimento), considerando-se que o emprego isolado do DSM-IV , ou do CID-10, é insuficiente para o fim a que se propõe; (2) um conhecimento psicanalítico para contemplar a pessoa, sua dinâmica e os movimentos presentes, diferentemente do trabalho cognitivocomportamental, que é um trabalho pontual e (3) maior esclarecimento, em nível universitário, do que constitui cada uma das áreas em questão.

Constatamos que existe um reconhecimento real, por parte tanto de psicólogos quanto de psiquiatras, da necessidade de ampliação de seus conhecimentos sobre a área complementar, pois isso pode facilitar o funcionamento de cada uma delas no contexto do trabalho multidisciplinar, sem que haja um predomínio de um saber sobre o outro. Essas posições são concordes com nossa visão inicial, uma vez que tal necessidade foi também por nós sentida, ainda no momento da elaboração do projeto, para um melhor entendimento acerca do que estávamos pesquisando. E, principalmente, porque acreditamos que, longe de criar embaraços, esta condição de ampliação de conhecimentos entre as áreas pode promover maior entendimento e menos disputas de posição na equipe, resultando em um ambiente agradável de convívio e um maior respeito entre seus membros.

\section{Considerações Finais}

Isso posto, o fato dessas questões existirem constitui-se para nós, psicólogos, em um estímulo à continuidade deste trabalho, pois, aliadas a novas posições de psiquiatras da área, que apresentam uma visão mais ampla de tais questões e maior disponibilidade para o aspecto psicoterapêutico, nos direcionam em busca do conhecimento necessário para bem participar de uma equipe multidisciplinar e assim poder, em conjunto com aqueles profissionais, proporcionar um melhor atendimento ao foco de todas as nossas atenções: o paciente.

\section{Referências}

American Psychiatric Association (2000). Diagnostic and statistical manual of mental disorders: DSM-IV ( $4^{\underline{a}}$ ed.). Washington DC: Autor.

Andrade, A. G., Castel, S., \& Hochgraf, P. B. (1995). Transtornos psiquiátricos associados ao uso de substâncias psicoativas. In M. R. Louzã Neto, T. Motta, Y. P. Wang, H. Elkis (Orgs.), Psiquiatria básica (pp. 121-135). Porto Alegre: Artes Médicas.

Bucher, R. (1992). O atendimento ao usuário de drogas. In R. Bucher (Org.), Drogas e drogadição no Brasil (pp. 229-256). Porto Alegre: Artes Médicas.

Castel, S. (1997). Fatores de predição de prognóstico de fármaco-depentendes avaliados pela escala de segmento de dependentes de substâncias psicoativas. Tese de doutorado não-publicada, Universidade de São Paulo, São Paulo.

Ferreira, M. P., Leite, M. C., Hochgraf, P. B., Zilberman, M. L. (2001). Dependências químicas. In T. A Cordás \& R. A. Moreno (Orgs.), Condutas em psiquiatria (4⿳亠口冋 ed., pp. 319-348). São Paulo: Lemos Editorial.

Fontanella, B. J. B., \& Turato, E. R. (2002). Barreiras na relação clínicopaciente em dependentes de substâncias psicoativas procurando tratamento. Revista de Saúde Pública, 36(4), 439-447.

Lefèvre, F., \& Lefèvre, A. M. C. (2003). O discurso do sujeito coletivo: um novo enfoque em pesquisa qualitativa (desdobramentos). Caxias do Sul: EDUCS.

Lucena, J. (1987). Algumas mudanças atuais no estilo de dependência de drogas. Neurobiologia, 50(2), 69-88.

World Health Organization (1993). Classificação de transtornos mentais e de comportamento da CID-10: descrições e diretrizes diagnósticas (pp. 6984). Porto Alegre: Artes Médicas.

${ }^{1}$ A presente pesquisa foi orientada pela Dra. Vera Lucia Gonçalves Beres.

Marli Ferreira Occhini, graduada em psicologia pela Universidade São Judas Tadeu, é psicóloga clínica em prática profissional privada. Endereço para correspondência: Rua Álvaro Peres, 57 (Eng. Goulart) São Paulo, SP; CEP 03726-190. E-mail: mocchini@uol.com.br

Marlene Galativicis Teixeira, graduada em Psicologia pela Universidade São Judas Tadeu, é pesquisadoracolaboradora no Programa de Atenção às Tentativas de Suicídio e assistente de pesquisa no Núcleo de Epidemiologia Psiquiátrica do Hospital das Clínicas da Faculdade de Medicina da Universidade de São Paulo. E-mail:mteixeira_psi@yahoo.com.br 